\title{
Association of Genetic Polymorphisms in TNFRSF11 with the Progression of Genetic Susceptibility to Gastric Cancer
}

\author{
Yu Fan $\mathbb{D D}^{1}{ }^{1}$ Xuyu Gu $\mathbb{D}^{1},{ }^{1}$ Huiwen Pan $\mathbb{D}^{1},{ }^{1}$ Zhe Dai $\mathbb{D}^{1},{ }^{1}$ Chen Zou $\mathbb{D}^{1},{ }^{1}$ Zhenjun Gao $\mathbb{D}^{2}{ }^{2}$ \\ and Heng Zhang $\mathbb{D}^{3}$ \\ ${ }^{1}$ Cancer Institute, The Affiliated People's Hospital of Jiangsu University, Zhenjiang, Jiangsu, China \\ ${ }^{2}$ Digestive Department, Qingpu Branch Hospital of Affiliated Zhongshan Hospital, Fudan University, Shanghai, China \\ ${ }^{3}$ Department of General Surgery, Nanjing Lishui District People's Hospital, Zhongda Hospital Lishui Branch, \\ Southeast University, Nanjing, China
}

Correspondence should be addressed to Chen Zou; tigerzou@126.com, Zhenjun Gao; gao.zhenjun@qphospital.com, and Heng Zhang; zhangheng1975@163.com

Received 29 February 2020; Revised 10 May 2020; Accepted 1 June 2020; Published 22 June 2020

Academic Editor: Thomas E. Adrian

Copyright (c) $2020 \mathrm{Yu}$ Fan et al. This is an open access article distributed under the Creative Commons Attribution License, which permits unrestricted use, distribution, and reproduction in any medium, provided the original work is properly cited.

\begin{abstract}
Objective. To investigate the relationship between polymorphism of TNFRSF11 gene $r s 9533156$ and $r s 2277438$ and susceptibility to gastric cancer. Methods. A case-control study was conducted to select 577 cases of primary gastric cancer and 678 cases of normal control. We extracted whole blood genomic DNA and amplified the target gene fragment by PCR. The genotyping and allele were tested through the snapshot method. Results. In this case-control study, we observed that there was a difference in the genotype distribution of TNFRSF11 gene rs9533156 between the case group and the control group. The frequency distribution of TC heterozygous mutation in the case group was higher than that in the control group. The smoking rate in the case group (34.49\%) was higher than that in the control group (27.29\%), and the difference in frequency distribution between the two groups was statistically significant $(P=0.006)$. Our findings suggest that TNFRSF11 rs 9533156 is associated with susceptibility to GC, which is more evident among elderly patients (>62 years), nonsmokers, and patients who do not consume alcohol. The analysis of the relationship between the TNFSF11 gene rs9533156 site variant and clinical factors of gastric cancer showed that, compared with the tumor size $<2 \mathrm{~cm}$ group, patients with tumor size $\geq 2 \mathrm{~cm}$ and whom carrying $r s 9533156$ site mutations had a higher frequency distribution, and the difference was statistically significant $(P=0.022)$. Compared with the nonhyperglycemic group, the frequency distribution of patients with $r s 9533156$ site mutations in the diabetes group was higher, and the difference was statistically significant $(P<0.001)$. Conclusion. This study shows that there is a correlation between smoking and the occurrence of gastric cancer. Based on our research, the functional SNP TNFRSF11 TC genotype may be an indicator of individual susceptibility to GC. The mutation at $r s 9533156$ may be related to the size of gastric cancer. The mutation rate of $r s 9533156$ of TNFSF11 gene is higher in diabetic gastric cancer patients.
\end{abstract}

\section{Introduction}

Gastric cancer is one of the most common malignant tumors in China. Due to its insidious onset and the current lack of effective early diagnostic molecular markers, patients often found to be advanced, resulting in a 5-year survival rate $<25 \%$. Local and distant metastasis of gastric cancer is the main reason for the low survival rate in patients with gastric cancer. Invasion and metastasis of gastric cancer is a complicated process involving multiple factors such as tumor biological behavior, metastasis pathway, and characteristics of metastatic organs. And individual genetic factors play an important role. Single nucleotide polymorphism (SNP) refers to the polymorphism of DNA sequence caused by the variation of a single nucleotide in the genome, which is the most common form of human genetic variation, accounting for more than $90 \%$ of all known polymorphisms [1]. Single nucleotide polymorphisms (SNPs) can regulate gene function and expression and has become an effective tool and means of genetic research. TNFRSF11 (tumor 
necrosis factor (ligand) superfamily member11), also known as OPGL (osteoprotegerin ligand) and RANKL (receptor activator of NF- kappa B ligand), is a type II transmembrane protein expressed on the surface of bone marrow stromal cells, osteoblasts, T lymphocytes, etc. [2-4]. TNFRSF11 is expressed in different organs of the human body, such as liver, bone, muscle, intestinal tract, adrenal gland, and other tissues [5]. TNFRSF11 (RANK) was initially identified and demonstrated to play a role in bone dissolution and lymph node development mainly through the RANK/RANKL/ OPG pathway [6].

Recently, the RANK/RANKL/OPG system has been observed to play a key role in tumor cell migration and invasion [7-9]. Studies have shown that TNFRSF11(RANK) is expressed in a variety of tumor tissues, such as osteosarcoma [10, 11], chondrosarcoma [12], breast cancer [13], prostate cancer $[14,15]$, renal cancer [16], oral squamous cell carcinoma [17], lung cancer [18], thyroid cancer [19], and melanoma [20]. However, the expression of TNFRSF11 in gastric cancer cells is rarely reported, and there is no report on the relationship between TNFRSF11 gene polymorphism and gastric cancer. Therefore, the present study used a casecontrol method to compare the genotypes and alleles of TNFRSF11 gene rs9533156 and rs2277438 in gastric cancer patients and healthy controls to analyze the relationship between TNFRSF11 gene polymorphism and gastric cancer susceptibility. At the same time, combined with the patient's clinical parameters, such as gender, age, smoking history, and drinking history, we can analyze the correlation between them comprehensively thus providing a theoretical basis for early screening and early treatment of gastric cancer.

\section{Research Object}

A total of 577 patients (case group) with gastric cancer admitted to Zhenjiang First People's Hospital from May 2013 to June 2017 were included. The average age of the case group was 61.34 11.097 years, including 394 males and 183 females, all of whom are Chinese, ethnic Han. All cases were clinically and pathologically confirmed to be gastric cancer, and all cases were primary gastric cancer, excluding secondary or recurrent tumors and other malignant tumors. None of the patients underwent radiotherapy or chemotherapy. A total of 678 healthy physical examinees from the physical examination center of Zhenjiang First People's Hospital were selected as the control group. The average age of the people in the control group was $62.31 \pm 7.549$ years old, including 456 males and 222 females. The people in the control group had no previous genetic history of the tumor. The control group was matched with the case group in terms of gender and age (there was no statistically significant difference in the $t$-test distribution of age and gender between the two groups $(P>0.05))$, and there was no blood relationship between the two groups.

\section{Research Method}

We followed the methods of Ding et al. [21]. Relevant disease history information of all study subjects was collected by researchers who had all been uniformly trained before. Also, double-entry and logical proofreading were used to ensure the accuracy of the input information. The experimental equipment was provided by the central laboratory of Zhenjiang First People's Hospital, and the main reagents were procured from the Furui Bioengineering Co., Ltd., Shanghai. The whole experiment process was guided and carried out by specialized and licensed laboratory technology operators to reduce any possible errors that might occur throughout the process, improving the accuracy of the results. $2 \mathrm{ml}$ peripheral venous blood of all study subjects from two groups was collected by professional nurses strictly following the principle of sterilization. Then, peripheral blood samples were processed with EDTA anticoagulation and stored at $-20^{\circ} \mathrm{C}$ for later use. After the centrifuge of the plasma, genomic DNA was extracted according to the instructions provided. Before being applied to further experiment, the purity of extracted genomic DNA needed to be determined. Any samples that did not meet the ratio requirements were discarded. The genomic DNA was extracted again until the ratios of OD280/OD230 and OD260/OD280 reached the normal ratio requirements for the experiment. Therefore, it can be ensured that the extracted DNA samples all met the experimental requirements. Primer Premier 5 software was applied in combination with the NCBI database to design upper and lower primers and snapshot extension primers of TNFRSF11 gene rs9533156 and rs2277438, respectively. The primers were synthesized with technology help from the Furui Bioengineering Co., Ltd., Shanghai. TNFRSF11-rs9533156 F: 5' AACTGTATCATCAGCTTCGTGT-3'. The content of $\mathrm{G}+\mathrm{C}$ was $40.91 \%$, and the Tm value was $57.81^{\circ} \mathrm{C}$. TNFRSF11rs9533156 R: 5'-TGAAGGTGACATTGAGCGAGG-3'. The content of $\mathrm{G}+\mathrm{C}$ was $52.38 \%$, and the Tm value was $60.34^{\circ} \mathrm{C}$. The product with a length of $190 \mathrm{bp}$ was obtained by PCR amplification. TNFRSF11-rs2277438 F: 5'-CCTGTGGATGATAGTCAGTTACTCG-3'. The $\mathrm{G}+\mathrm{C}$ content is $48.00 \%$, and the Tm value was $60.51 \%$. TNFRSF11-rs2277438 R: $5^{\prime}$ AGGAGGAGAAACAGTAAGGACG-3'. The G+C content was $50.00 \%$, and the Tm value was $59.17 \%$. The length of the product was $201 \mathrm{bp}$ by PCR amplification. The PCR amplification products were purified by ExoI and FastAP for extension reaction, and the genotyping was performed with the ABI3730XL sequencing apparatus after. Allele-specific primer extension was performed with ddNTP labeled with fluorescent dye using the snapshot method for the detection of gene polymorphism. The snapshot method mainly consists of three basic steps: amplification, primer extension, and analysis. Genotyper or GeneMapper software designed for the observed peak color and fragment length range can be used for automated allele analysis. For quality control, 5\% of samples were randomly selected for reinspection to ensure the accuracy of the test results.

\section{Statistical Method}

The data were analyzed by using SPSS 20.0 software (SPSS Inc., Chicago, Illinois, USA). The frequency of genotype distribution in the control group and case group was tested 
using the Hardy-Weinberg genetic balance test. Chi-square test was used to compare the correlation between genotype and allele frequency distribution and NSCL/P and calculate the $X^{2}$ value and $P$ value. Binary logistic regression analysis was used to calculate the odds ratio (OR) and its 95\% confidence interval (CI) to analyze the relative risk of disease caused by genotyping or alleles at polymorphic sites. The statistical tests were all two-sided probability tests; $P<0.05$ was considered statistically significant.

\section{Results}

The results in Table 1 show the basic information of the TNFRSF11 gene $r s 9533156$ and $r s 2277438$ polymorphism: the genotype frequency distribution of the control group Hardy-Weinberg equilibrium ( $P$ value for HWE, all $P>0.05$, Table 1).

The results in Table 2 show the characteristics of the study subjects, including demographics and environmental risk factors. The smoking rate was much higher in the case group as compared with the control group (34.49\% versus $27.29 \%, P=0.006$ ). The demographics (age and sex) were well matched $(P=0.635$ and $P=0.698$, respectively). That indicated the occurrence and development of smoking and gastric cancer. The drinking rate was lower in the case group as compared with the control group, but there was no statistically significant difference between the two groups (21.49\% versus $23.30 \%, P=0.443$ ).

The results in Table 3 show that the frequency distribution and logistic regression analysis of the $r s 2277438$ polymorphism of TNFSF11 gene in gastric cancer and control group showed that the wild-type AA was used as the reference type, and the frequency distribution of AG heterozygous mutant type at $r s 2269700$ was higher in the control group than that in the case group $(43.76 \%>41.19 \%)$. However, although the difference between the two groups was not statistically significant $(P=0.310)$, after logistic regression adjustment analysis based on gender, age, smoking, and drinking, there was still no statistical difference but it was closer to the difference than the results before the regression $(P=0.263)$. The frequency distribution of GG homozygous mutants was also not statistically significant $(P=0.919)$, and there was no statistical difference after logistic regression adjustment $(P=0.427)$. In the dominant model, the frequency distribution of AG + GG mutations was not statistically significant in the case-control group $(P=0.947)$, and the difference was not statistically significant after regression adjustment $(P=0.228)$. In the recessive model, the frequency distribution was not statistically different $(P=0.822)$. According to gender, age, smoking, and drinking, after logistic regression analysis, there was still no statistical difference between the two groups $(P=0.681)$.

The results in Table 4 show that the results of the frequency distribution and logistic regression analysis of TNFRSF11 gene rs9533156 in gastric cancer and control group showed that the difference between the two groups with the wild-type TT as the reference type was statistically significant $(P=0.044)$, and the difference was statistically significant after logistic regression analysis adjusted according to gender, age, smoking, and drinking $(P=0.039)$. There was no statistically significant difference in the frequency distribution of CC homozygous mutant $(P=0.318)$, and there was no statistically significant difference after logistic regression analysis $(P=0.294)$. In the distribution of the dominant model $\backslash$ recessive model, there was no statistical difference $(P=0.062 ; 0.056)$. According to logistic regression analysis, there was still no statistical difference $(P=0.918 ; 0.909)$.

The results in Table 5 show that, compared with the frequency distribution of the A allele in rs2277438, the G allele was lower in the case group than that in the control group $(29.84 \%<31.50 \%)$, but the difference was not statistically significant $(P=0.372)$. Also, the frequency distribution of the $\mathrm{C}$ allele in rs9533156 was not statistically significant in the case-control group $(P=0.264)$.

The results in Table 6 show that, according to stratification results, the polymorphism of TNFRSF11 gene rs2277438 showed that, with wild-type AA as a reference genotype, there was no statistical significance in the distribution of heterozygous AG and homozygous TT. In the dominant model and recessive model, the difference in gene distribution was not statistically significant. And no significant differences were found in wild-type TC, homozygous TT, dominant models, and recessive models after stratified analysis according to gender, age, smoking, and drinking factors.

Table 7 summarizes the results of the association between TNFRSF11 gene rs9533156 polymorphism and GC risk in the stratified analysis. In the elderly ( $\geq 62$ years old) group, the frequency distribution of TC heterozygous mutations was statistically different between the two groups $(P=0.002)$, and the risk of gastric cancer in the TC group was 1.83 times higher than that of the TT type. TC mutant mutation may be a risk factor for gastric cancer. In the c-dominated dominance model, the frequency distribution of TC + CC was statistically different between the two groups $(P=0.004)$, and the risk of developing gastric cancer in the $\mathrm{TC}+\mathrm{CC}$ group was 1.70 times higher than that in the TT group. The c-dominated TC + CC group may be a risk factor. In the nonsmoker group, the frequency distribution of TC heterozygous mutations was statistically different between the two groups $(P=0.017)$, and the risk of gastric cancer in the TC group was 1.49 times higher than that of the TT type. In the c-dominated dominance model, the frequency distribution of TC + CC was statistically different between the two groups $(P=0.016)$, and the risk of developing gastric cancer in the TC + CC group was 1.46 times higher than that in the TT group. In the group of nondrinkers, the frequency distribution of TC heterozygous mutations was statistically different between the two groups ( $P=0.043)$, and the risk of gastric cancer in the TC group was 1.37 times higher than that of the TT type. In the c-dominated dominance model, the frequency distribution of TC + CC was statistically different between the two groups $(P=0.037)$, and the risk of developing gastric cancer in the TC + CC group was 1.36 times higher than that in the TT group.

The results in Table 8 show that TNFSF11 gene rs 9533156 site variants and gastric cancer clinical factor analysis results 
TABLE 1: Primary information of TNFRSF11 gene $r s 9533156, r s 2277438$ polymorphisms.

\begin{tabular}{|c|c|c|c|c|c|c|c|c|}
\hline $\begin{array}{l}\text { Genotyped } \\
\text { SNPs }\end{array}$ & Gene & $\begin{array}{c}\text { Chr pos } \\
\text { (NCBI build } \\
38)\end{array}$ & Category & $\begin{array}{c}\text { MAF }^{\mathrm{a}} \text { for } \\
\text { Chinese in } \\
\text { database }\end{array}$ & $\begin{array}{c}\text { MAF in our } \\
\text { controls } \\
(n=678)\end{array}$ & $\begin{array}{l}P \text { value for } \\
\text { HWE }^{\mathrm{b}} \text { test in } \\
\text { our controls }\end{array}$ & $\begin{array}{l}\text { Genotyping } \\
\text { method }\end{array}$ & $\begin{array}{c}\text { Genotyping value } \\
(\%)\end{array}$ \\
\hline rs9533156 & 13 & TNFRSF11 & Intron_variant & 0.439 & 0.315 & 0.719 & & 98.64 \\
\hline rs 2277438 & 13 & TNFRSF11 & Intron_variant & 0.300 & 0.463 & 0.374 & Snapshot & 95.94 \\
\hline
\end{tabular}

${ }^{\mathrm{a}}$ Minor allele frequency and ${ }^{\mathrm{b}}$ Hardy-Weinberg equilibrium.

Table 2: Distribution of selected demographic variables and risk factors in gastric cancer cases and controls.

\begin{tabular}{|c|c|c|c|}
\hline & $\begin{array}{c}\text { Overall cases }(n=577) \\
n(\%)\end{array}$ & $\begin{array}{c}\text { Overall controls }(n=678) \\
n(\%)\end{array}$ & $P$ \\
\hline Age (years) & $61.34 \pm 11.097$ & $62.31 \pm 7.549$ & 0.065 \\
\hline \multicolumn{4}{|l|}{ Age (years) } \\
\hline$<62$ & $268(46.45)$ & $324(47.79)$ & \\
\hline$\geq 62$ & $309(53.55)$ & $354(52.21)$ & 0.635 \\
\hline \multicolumn{4}{|l|}{ Sex } \\
\hline Male & $394(68.28)$ & $456(67.26)$ & \\
\hline Female & $183(31.72)$ & $222(32.74)$ & 0.698 \\
\hline \multicolumn{4}{|c|}{ Smoking status } \\
\hline Never & $378(65.51)$ & $493(72.71)$ & \\
\hline Ever & $199(34.49)$ & $185(27.29)$ & 0.006 \\
\hline \multicolumn{4}{|l|}{ Alcohol use } \\
\hline Never & $453(78.51)$ & $520(76.70)$ & \\
\hline Ever & $124(21.49)$ & $158(23.30)$ & 0.443 \\
\hline
\end{tabular}

TABLE 3: TNFRSF11 gene rs2277438 polymorphism in GC cases and controls and logistic regression analysis.

\begin{tabular}{|c|c|c|c|c|c|c|c|c|}
\hline \multirow[t]{2}{*}{ Genotype } & \multicolumn{2}{|c|}{$\begin{array}{c}\text { GC cases } \\
(n=577)\end{array}$} & \multicolumn{2}{|c|}{$\begin{array}{l}\text { Controls } \\
(n=678)\end{array}$} & \multirow{2}{*}{$\begin{array}{c}\text { Crude OR } \\
(95 \% \text { CI })\end{array}$} & \multirow[t]{2}{*}{$P$} & \multirow{2}{*}{$\begin{array}{l}\text { Adjusted OR } \\
\quad(95 \% \mathrm{CI})\end{array}$} & \multirow[t]{2}{*}{$P$} \\
\hline & $n$ & $(\%)$ & $n$ & $(\%)$ & & & & \\
\hline \multicolumn{9}{|l|}{$r s 2277438$} \\
\hline AA & 284 & 49.56 & 310 & 46.62 & 1.00 & & 1.00 & \\
\hline AG & 236 & 41.19 & 291 & 43.76 & $1.13(0.89-1.43)$ & 0.310 & $0.87(0.69-1.11)$ & 0.263 \\
\hline GG & 53 & 9.25 & 64 & 9.62 & $1.02(0.68-1.53)$ & 0.919 & $0.92(0.75-1.13)$ & 0.427 \\
\hline $\mathrm{AG}+\mathrm{GG}$ & 289 & 50.44 & 355 & 53.38 & $1.00(0.80-1.27)$ & 0.947 & $0.93(0.83-1.04)$ & 0.228 \\
\hline GG & 53 & 9.25 & 64 & 9.62 & $0.96(0.65-1.40)$ & 0.822 & $0.96(0.79-1.17)$ & 0.681 \\
\hline $\mathrm{AA}+\mathrm{AG}$ & 520 & 90.75 & 601 & 90.38 & 1.001 & & 1.00 & \\
\hline
\end{tabular}

TABLE 4: TNFRSF11 gene rs9533156 polymorphism in GC cases and controls and logistic regression analysis.

\begin{tabular}{|c|c|c|c|c|c|c|c|c|}
\hline \multirow[t]{2}{*}{ Genotype } & \multicolumn{2}{|c|}{$\begin{array}{l}\text { GC cases } \\
(n=577)\end{array}$} & \multicolumn{2}{|c|}{$\begin{array}{l}\text { Controls } \\
(n=678)\end{array}$} & \multirow{2}{*}{$\begin{array}{c}\text { Crude OR } \\
(95 \% \mathrm{CI})\end{array}$} & \multirow[t]{2}{*}{$P$} & \multirow{2}{*}{$\begin{array}{l}\text { Adjusted OR } \\
\quad(95 \% \mathrm{CI})\end{array}$} & \multirow[t]{2}{*}{$P$} \\
\hline & $n$ & (\%) & $n$ & (\%) & & & & \\
\hline \multicolumn{9}{|l|}{$r s 9533156$} \\
\hline $\mathrm{TT}$ & 139 & 24.91 & 192 & 29.72 & 1.00 & & 1.00 & \\
\hline $\mathrm{TC}$ & 296 & 53.05 & 310 & 47.99 & $1.32(1.00-1.73)$ & 0.044 & $1.33(1.02-1.75)$ & 0.039 \\
\hline $\mathrm{CC}$ & 123 & 22.04 & 144 & 22.29 & $1.18(0.85-1.63)$ & 0.318 & $1.09(0.93-1.29)$ & 0.294 \\
\hline $\mathrm{TC}+\mathrm{CC}$ & 419 & 75.09 & 454 & 70.28 & $1.28(0.99-1.65)$ & 0.062 & $1.13(0.99-1.29)$ & 0.056 \\
\hline $\mathrm{CC}$ & 123 & 22.04 & 144 & 22.29 & $0.99(0.75-1.30)$ & 0.918 & $0.99(0.86-1.14)$ & 0.909 \\
\hline $\mathrm{TT}+\mathrm{TC}$ & 435 & 77.96 & 502 & 77.71 & 1.00 & & 1.00 & \\
\hline
\end{tabular}

show that, compared with the tumor size $<2 \mathrm{~cm}$ group, patients with tumor size $\geq 2 \mathrm{~cm}$ and carrying rs9533156 site mutations had a higher frequency distribution, and the difference was statistically significant $(P=0.022)$. This suggests that $r s 9533156$ mutation may be related to the size of gastric cancer. Compared with the nonhyperglycemic group, the frequency distribution of patients with hyperglycemia (diabetes group) who also carry the rs9533156 mutation is higher, and the difference was statistically significant $(P<0.001)$. This suggests that hyperglycemia and rs9533156 site mutation are related risk factors for gastric cancer. There was no significant correlation between 
TABLE 5: Analysis of $r s 9533156$ and $r s 2277438$ alleles between cases and controls.

\begin{tabular}{llcccr}
\hline Locus & Variable & Case & Control & $P$ & OR (95\% CI) \\
\hline \multirow{2}{*}{$r s 2277438$} & A allele & $804(70.16)$ & $911(68.50)$ & & \\
& G allele & $342(29.84)$ & $419(31.50)$ & 0.372 & $0.93(0.78-1.09)$ \\
\hline \multirow{2}{*}{ rs 9533156} & T Allele & $574(51.43)$ & $694(53.72)$ & & \\
& C Allele & $542(48.57)$ & $598(46.28)$ & 0.264 & $1.09(0.93-1.29)$ \\
\hline
\end{tabular}

TABLE 6: Stratified analyses between $r s 2277438$ polymorphism and risk by sex, age, smoking status, and alcohol consumption.

\begin{tabular}{|c|c|c|c|c|c|c|c|c|}
\hline \multirow{2}{*}{ Variable } & \multicolumn{3}{|c|}{ (Case/control) } & \multicolumn{3}{|c|}{ Adjusted OR (95\% CI); $P$} & \multirow{2}{*}{$\begin{array}{c}(\mathrm{AG}+\mathrm{GG}) \\
\mathrm{VSAA}\end{array}$} & \multirow{2}{*}{$\begin{array}{c}\text { GGVS } \\
(\mathrm{AA}+\mathrm{AG})\end{array}$} \\
\hline & $\mathrm{AA}$ & AG & GG & $\mathrm{AA}$ & $\mathrm{AG}$ & GG & & \\
\hline \multicolumn{9}{|l|}{ Sex } \\
\hline Male & $198 / 201$ & $157 / 198$ & $36 / 45$ & 1.00 & $\begin{array}{c}0.81(0.60-1.07) \\
P: 0.138\end{array}$ & $\begin{array}{c}0.81(0.50-1.31) \\
P: 0.395\end{array}$ & $\begin{array}{c}0.81(0.61-1.06) \\
P: 0.121\end{array}$ & $\begin{array}{c}0.90(0.57-1.43) \\
P: 0.651\end{array}$ \\
\hline Female & $86 / 109$ & $79 / 93$ & $17 / 19$ & 1.00 & $\begin{array}{c}1.08(0.71-1.63) ; \\
P: 0.725\end{array}$ & $\begin{array}{c}1.13(0.56-2.31) \\
P: 0.729\end{array}$ & $\begin{array}{c}1.09(0.73-1.61) \\
P: 0.679\end{array}$ & $\begin{array}{c}1.09(0.55-2.18) \\
P: 0.795\end{array}$ \\
\hline \multicolumn{9}{|l|}{ Age } \\
\hline$<62$ & $129 / 146$ & $108 / 138$ & $29 / 31$ & 1.00 & $\begin{array}{c}0.89(0.63-1.25) \\
P: 0.491\end{array}$ & $\begin{array}{c}1.06(0.61-1.85) \\
P: 0.841\end{array}$ & $\begin{array}{c}0.92(0.66-1.27) \\
P: 0.606\end{array}$ & $\begin{array}{c}1.12(0.66-1.91) ; \\
P: 0.675\end{array}$ \\
\hline$\geq 62$ & $155 / 164$ & $128 / 153$ & $24 / 33$ & 1.00 & $\begin{array}{c}0.89(0.64-1.22) \\
P: 0.457\end{array}$ & $\begin{array}{c}0.77(0.44-1.36) \\
P: 0.367\end{array}$ & $\begin{array}{c}0.87(0.64-1.18) ; \\
P: 0.353\end{array}$ & $\begin{array}{c}0.82(0.47-1.41) \\
P: 0.464\end{array}$ \\
\hline \multicolumn{9}{|c|}{ Smoking status } \\
\hline Never & $189 / 230$ & $154 / 207$ & $33 / 49$ & 1.00 & $\begin{array}{c}0.91(0.68-1.20) \\
P: 0.492\end{array}$ & $\begin{array}{c}0.82(0.51-1.33) \\
P: 0.417\end{array}$ & $\begin{array}{c}0.89(0.68-1.16) \\
P: 0.392\end{array}$ & $\begin{array}{c}0.86(0.50-1.36) \\
P: 0.517\end{array}$ \\
\hline Ever & $95 / 80$ & $82 / 84$ & $20 / 15$ & 1.00 & $\begin{array}{c}0.82(0.54-1.26) \\
P: 0.367\end{array}$ & $\begin{array}{c}1.12(0.54-2.24) ; \\
P: 0.757\end{array}$ & $\begin{array}{c}0.87(0.58-1.30) \\
P: 0.493\end{array}$ & $\begin{array}{c}1.24(0.61-2.49) \\
P: 0.555\end{array}$ \\
\hline \multicolumn{9}{|c|}{ Alcohol consumption } \\
\hline Never & $223 / 237$ & $182 / 224$ & $46 / 52$ & 1.00 & $\begin{array}{c}0.86(0.66-1.13) \\
P: 0.283\end{array}$ & $\begin{array}{c}0.94(0.61-1.46) \\
P: 0.782\end{array}$ & $\begin{array}{c}0.88(0.68-1.31) \\
P: 0.314\end{array}$ & $\begin{array}{c}1.01(0.66-1.53) ; \\
P: 0.974\end{array}$ \\
\hline Ever & $61 / 73$ & $54 / 67$ & $7 / 12$ & 1.00 & $\begin{array}{c}0.97(0.59-1.58) ; \\
P: 0.886\end{array}$ & $\begin{array}{c}0.70(0.26-1.88) ; \\
P: 0.476\end{array}$ & $\begin{array}{c}0.94(0.58-1.51) \\
P: 0.796\end{array}$ & $\begin{array}{c}0.71(0.27-1.86) ; \\
P: 0.485\end{array}$ \\
\hline
\end{tabular}

TABLE 7: Stratified analyses between $r s 9533156$ polymorphism and risk by sex, age, smoking status, and alcohol consumption.

\begin{tabular}{|c|c|c|c|c|c|c|c|c|}
\hline \multirow{2}{*}{ Variable } & \multicolumn{3}{|c|}{ (Case/control) } & \multicolumn{3}{|c|}{ Adjusted OR (95\% CI); $P$} & \multirow{2}{*}{$(\mathrm{TC}+\mathrm{CC}) \mathrm{VSTT}$} & \multirow{2}{*}{ CCVS $(\mathrm{TT}+\mathrm{TC})$} \\
\hline & TT & TC & $\mathrm{CC}$ & TT & TC & $\mathrm{CC}$ & & \\
\hline \multicolumn{9}{|l|}{ Sex } \\
\hline Male & $91 / 129$ & $206 / 210$ & $84 / 95$ & 1.00 & $\begin{array}{c}1.39(1.00-1.93) \\
P: 0.050\end{array}$ & $\begin{array}{c}1.25(0.84-1.87) \\
P: 0.265\end{array}$ & $\begin{array}{c}0.93(0.67-1.30) \\
P: 0.671\end{array}$ & $\begin{array}{c}1.01(0.72-1.41) ; \\
P: 0.957\end{array}$ \\
\hline Female & $48 / 63$ & $90 / 100$ & $39 / 49$ & 1.00 & $\begin{array}{c}1.18(0.74-1.89) ; \\
P: 0.488\end{array}$ & $\begin{array}{c}1.05(0.59-1.84) \\
P: 0.879\end{array}$ & $\begin{array}{c}1.14(0.73-1.77) \\
P: 0.572\end{array}$ & $\begin{array}{c}0.94(0.58-1.52) ; \\
P: 0.800\end{array}$ \\
\hline \multicolumn{9}{|l|}{ Age } \\
\hline$<62$ & $79 / 89$ & $118 / 143$ & $61 / 69$ & 1.00 & $\begin{array}{c}0.93(0.63-1.37) \\
P: 0.713\end{array}$ & $\begin{array}{c}0.99(0.63-1.58) \\
P: 0.986\end{array}$ & $\begin{array}{c}0.95(0.66-1.37) \\
P: 0.787\end{array}$ & $\begin{array}{c}1.00(0.68-1.48) ; \\
P: 0.997\end{array}$ \\
\hline$\geq 62$ & $60 / 103$ & $178 / 167$ & $62 / 75$ & 1.00 & $\begin{array}{c}1.83(1.25-2.68) ; \\
P: \mathbf{0 . 0 0 2}\end{array}$ & $\begin{array}{c}1.42(0.89-2.26) ; \\
P: 0.138\end{array}$ & $\begin{array}{c}1.70(1.18-2.45) \\
P: \mathbf{0 . 0 0 4}\end{array}$ & $\begin{array}{c}0.94(0.64-1.37) ; \\
P: 0.740\end{array}$ \\
\hline \multicolumn{9}{|c|}{ Smoking status } \\
\hline Never & $87 / 146$ & $201 / 227$ & $80 / 96$ & 1.00 & $\begin{array}{c}1.49(1.07-2.06) \\
P: \mathbf{0 . 0 1 7}\end{array}$ & $\begin{array}{c}1.40(0.94-2.08) ; \\
P: 0.098\end{array}$ & $\begin{array}{c}1.46(1.07-1.99) \\
P: \mathbf{0 . 0 1 6}\end{array}$ & $\begin{array}{c}1.08(0.77-1.51) ; \\
P: 0.654\end{array}$ \\
\hline Ever & $52 / 46$ & $95 / 83$ & $43 / 48$ & 1.00 & $\begin{array}{c}1.01(0.62-1.66) ; \\
P: 0.961\end{array}$ & $\begin{array}{c}0.80(0.45-1.40) \\
P: 0.425\end{array}$ & $\begin{array}{c}0.93(0.59-1.48) \\
P: 0.765\end{array}$ & $\begin{array}{c}0.79(0.49-1.26) ; \\
P: 0.320\end{array}$ \\
\hline \multicolumn{9}{|c|}{ Alcohol consumption } \\
\hline Never & $109 / 153$ & $235 / 241$ & $96 / 101$ & 1.00 & $\begin{array}{c}1.37(1.01-1.86) \\
P: \mathbf{0 . 0 4 3}\end{array}$ & $\begin{array}{c}1.33(0.92-1.94) \\
P: 0.128\end{array}$ & $\begin{array}{c}1.36(1.02-1.81) \\
P: \mathbf{0 . 0 3 7}\end{array}$ & $\begin{array}{c}1.09(0.80-1.50) ; \\
P: 0.584\end{array}$ \\
\hline Ever & $30 / 39$ & $61 / 69$ & $27 / 43$ & 1.00 & $\begin{array}{c}1.15(0.64-2.07) \\
P: 0.642\end{array}$ & $\begin{array}{c}0.82(0.42-1.61) \\
P: 0.556\end{array}$ & $\begin{array}{c}1.02(0.59-1.77) \\
P: 0.940\end{array}$ & $\begin{array}{c}0.75(0.43-1.30) ; \\
P: 0.299\end{array}$ \\
\hline
\end{tabular}


TABLE 8: Clinic factors of rs9533156 polymorphism on gastric cancer development.

\begin{tabular}{|c|c|c|c|c|c|}
\hline Group & $\mathrm{TC}+\mathrm{CC}$ & TT & OR & $95 \% \mathrm{CI}$ & $P$ value \\
\hline \multicolumn{6}{|l|}{ Tumor size } \\
\hline$\geq 2 \mathrm{~cm}$ & $360(85.91)$ & $125(80.13)$ & & & \\
\hline$<2 \mathrm{~cm}$ & $59(14.09)$ & $31(19.87)$ & 1.751 & $1.078-2.845$ & 0.022 \\
\hline \multicolumn{6}{|l|}{ Tumor location } \\
\hline Fundus & $6(1.70)$ & $2(1.85)$ & & & \\
\hline Antrum & $256(72.52)$ & $82(75.93)$ & 0.961 & $0.190-4.853$ & 0.962 \\
\hline Body of the stomach & $91(25.78)$ & $24(22.22)$ & 0.791 & $0.150-4.171$ & 0.676 \\
\hline \multicolumn{6}{|l|}{ Tumor differentiation } \\
\hline Well & $12(3.47)$ & $2(1.71)$ & & & \\
\hline Moderate & $174(50.29)$ & $64(54.70)$ & 2.207 & $0.481-10.132$ & 0.368 \\
\hline Poor & $160(46.24)$ & $51(43.59)$ & 1.913 & $0.414-8.830$ & 0.528 \\
\hline \multicolumn{6}{|l|}{ Pathological pattern } \\
\hline Signet-ring cell carcinoma & $17(4.20)$ & $6(4.55)$ & & & \\
\hline Both & $5(1.23)$ & $4(3.03)$ & 0.178 & $0.183-0.991$ & 0.407 \\
\hline Adenocarcinoma & $383(94.57)$ & $122(92.42)$ & 0.903 & $0.348-2.340$ & 0.833 \\
\hline \multicolumn{6}{|l|}{ Blood glucose } \\
\hline Hyperglycemia & $114(27.21)$ & $16(11.51)$ & & & \\
\hline Nonhyperglycemia & 305 (72.79) & $123(88.49)$ & 2.870 & $1.635-5.048$ & $<0.001$ \\
\hline
\end{tabular}

rs9533156 and the location, differentiation, and pathological type of gastric cancer. However, there is no statistical association between the rs2277438 locus variant and the clinical factors of gastric cancer.

\section{Discussion}

Gastric cancer is a multifactorial disease including diet, genetic factors, environmental factors, immune factors, infections, and inflammation. SNP can modulate gene function and/or expression, and SNP-association studies may provide important insights into the pathogenesis of gastric cancer. At present, studies on the TNFRSF11 gene mainly focus on the effect and mechanism of RANK/ RANKL/OPG bone regulatory pathway on osteoporosis/ fracture healing, while there are few studies on the polymorphism of TNFRSF11 gene. Castilhos et al. [22] found that the longer roots of upper central incisors and rapid maxillary expansion, as well as allele A of the rs3102724 polymorphism of the OPG gene and EARR, were associated with EARR in Brazil's white people. MrozikiewiczRakowska et al. [23] found that the following variants TNFRSF11 B (rs2073618, rs2073617, rs1872426, rs1032128, rs7464496, rs11573829, and rs1485286), COLEC10 (rs6993813 and rs3134069), and TNFSF11 (rs9533156) present differences in allele frequencies in diabetic foot patients and show correlation with gender, diabetes type, and diabetic foot etiology. Casas-Avila et al. [24] found that carrying the GG genotype of rs12585014 entails a higher risk of having menarche later ( $>13$ years), which could involve a greater risk of fractures. The rs3018362 and rs12585014 do not seem to be associated with hip osteoporosis or hip fracture in Mexican women. Sassi et al. [25] also found the association of the-643-c $>$ T polymorphism with BMD variation and osteoporosis risk in postmenopausal Tunisian women. Shaker and Senousy [26] found that there are interactions between RANKL-rs9533156 and
OPG-rs2073618. A stronger combined effect of SNPs in RANKL and OPG genes via gene-gene interaction may help predict breast cancer risk and prognosis. Lucas Corso et al. [27] found that the polymorphism rs2073618 of OPG is a possible marker that is associated with the risk of the manifestation of TMJ ankylosis. Our team [28] also found that functional SNP RNK rs $1805034 \mathrm{~T}>\mathrm{C}$ may be an indicator of susceptibility to esophageal squamous cell carcinoma (ESCC). However, the correlation between TNFRSF11 gene polymorphism and gastric cancer susceptibility has not been reported.

In this study, we selected 577 gastric cancer patients and 678 healthy volunteers to explore the relationship between TNFRSF11 gene rs9533156 and rs2277438 loci and gastric cancer susceptibility in Chinese Han population. This study found that smoking was correlated with the occurrence and development of gastric cancer and was an independent risk factor for gastric cancer. However, there was no significant difference in the distribution of alcohol consumption between the two groups. In this hospital-based case-control study of GC, we investigated the association of TNFRSF11 gene rs9533156 and rs2277438 polymorphism with the risk of GC. We found that the TNFRSF11 gene rs9533156 TC SNP was significantly associated with an increased risk of GC. It is worth noting that elderly patients ( $>62$ years old) carrying the rs9533156 TC genotype of TNFSF11 gene, nonsmokers, and patients who do not drink alcohol have an increased risk of GC after stratification analyses.

In a further study on the relationship between TNFSF11 gene locus and clinical parameters of gastric cancer, we found that rs9533156 mutation may be related to the tumor size of gastric cancer. Compared with the group with tumor size $<2 \mathrm{~cm}$, the patients with tumor size $\geq 2 \mathrm{~cm}$ carrying rs9533156 mutation at the same time had higher frequency distribution, and the difference was statistically significant. This also confirms our previous research conclusion that rs9533156 TC genotype may be a risk factor for gastric 
cancer. Compared with the nonhyperglycemia group, the frequency distribution of the patients with hyperglycemia (diabetes group) carrying rs9533156 mutation at the same time was higher, and the difference was statistically significant. There was no significant correlation between rs9533156 mutation and tumor location, and differentiation degree and pathological type. There was no significant correlation between rs2277438 and clinical factors of gastric cancer.

To our knowledge, this study is the first to show a significant correlation between TNFRSF11 rs9533156 TC genotype and gastric cancer susceptibility. Although the association appears to be statistically significant, the findings need to be replicated in large independent samples to further confirm the role of TNFRSF11 in genetic susceptibility to gastric cancer. Several limitations of this study need to be addressed. First, the patients and controls were recruited from hospitals and may, therefore, not be representative of the general population. Second, the SNPs studied may not provide a comprehensive picture of the TNFRSF11 genetic variability. Third, Helicobacter pylori is generally regarded as the main cause of peptic ulcer disease and gastric adenocarcinoma. However, due to insufficient patient clinical information, we did not investigate Helicobacter pylori infection. Thus, the power of our analyses was restricted.

However, our study found that the mutation rate of rs9533156 in the TNFSF11 gene of diabetic gastric cancer patients is higher, suggesting that diabetes may be related to gastric cancer, and diabetic patients have a higher risk of gastric cancer. Previous studies have also found that patients with diabetes have an increased risk of cancer [29]. However, there are not many reports on the relationship between diabetes and gastric cancer. Whether type 2 diabetes increases the risk of gastric cancer remains controversial. Miao et al. [30] reported the data of 8559861 participants in a meta-analysis of 22 cohort studies and found that diabetes was an incentive to increase the risk of gastric cancer in men. However, other studies have reported conflicting results of women's cancer risk. Inoue et al. [31] conducted a group analysis in the 2011 meta-analysis and found that, compared with men with diabetes, women with diabetes had an $18 \%$ increased risk of stomach cancer.

In 2012, American and European scholars believed that type 2 diabetes had a significant positive effect on gastric cancer $[32,33]$. However, Khan et al. previously believed that type 2 diabetes can effectively reduce the incidence of gastric cancer [34]. Also, in a 2015 study by Xu et al., there was no significant correlation between the risk of gastric cancer and diabetes among men and women [35]. Increased levels of insulin and insulin-like growth factor 1 receptor in diabetic patients can promote cell division, inhibit apoptosis, and promote proliferation and differentiation [36]. Hyperglycemia can induce cell damage, and glycosylated substance can promote the production of oxygen free radicals and DNA damage [37]. Besides, glucose may act as a source of energy to promote the development of gastric cancer, especially for the types with rapid growth and a high degree of malignancy. Also, the immune function of patients with diabetes is reduced, the internal environment is disordered, and chronic inflammation and the use of drugs such as sulfonylurea, metformin, and insulin also increase the risk of gastric cancer. Of course, the mechanism that causes this correlation is not yet clear, and it may be related to multiple channels.

In conclusion, our study provides evidence that genotype mutation of TNFSF11 gene rs9533156 TC may be associated with GC risk. To confirm our findings, tissuespecific biology and large population replication studies are needed.

\section{Data Availability}

The data used to support the findings of this study are available from the corresponding author upon request.

\section{Ethical Approval}

The research was approved by the Ethics Review Committee of Jiangsu University.

\section{Consent}

All patients provided written informed consent.

\section{Disclosure}

Xuyu $\mathrm{Gu}$ is a co-first author.

\section{Conflicts of Interest}

The authors declare that they have no conflicts of interest.

\section{Acknowledgments}

This study was supported in part by the Jiangsu Innovative Team Leading Talent Fund (CXTDC2016006 and QNRC2016446), Natural Science Foundation of Jiangsu Province (BK20171304), Jiangsu Provincial Key Research and Development Special Fund (BE2015666); Jiangsu Six High Peak Talent Fund (WSW-205 and WSW236), Health Science and Technology Special Project of Zhenjiang (SHW2016004), Science and Technology Fund of High Tech Industrial Development Zone of Jiangyin (ZXQY201805), and Suqian Science and Technology Support Project Fund (S201721). In addition, the authors thank all participants of this study.

\section{References}

[1] S. S. Shah and M. K. Aghi, "The role of single-nucleotide polymorphisms in pituitary adenomas tumorigenesis," Cancers, vol. 11, no. 12, p. 1977, 2019.

[2] A. González-Mercado, J. Sánchez-López, F. Perea-Díaz et al., "Association of polymorphisms of the TNFRSF11B and TNFSF11 genes with bone mineral density in postmenopausal women from western Mexico," Archives of Medical Science, vol. 15, no. 5, pp. 1352-1356, 2019.

[3] E. Persson, P. P. C. Souza, T. Floriano-Marcelino, H. H. Conaway, P. Henning, and U. H. Lerner, "Activation of 
Shc1 allows oncostatin $M$ to induce RANKL and osteoclast formation more effectively than leukemia inhibitory factor," Frontiers Immunology, vol. 10, p. 1164, 2019.

[4] J. L. Zhang, X. M. Qiu, N. Zhang et al., "Bu-Shen-Ning-Xin decoction suppresses osteoclastogenesis by modulating RANKL/OPG imbalance in the CD4+ T lymphocytes of ovariectomized mice," International Journal of Molecular Medicine, vol. 42, no. 1, pp. 299-308, 2018.

[5] T. Ono, M. Hayashi, F. Sasaki, and T. Nakashima, "RANKL biology: bone metabolism, the immune system, and beyond," Inflammation and Regeneration, vol. 40, no. 1, 2020.

[6] Y. Zhao, H.-L. Wang, T.-T. Li, F. Yang, and C.-M. Tzeng, "Baicalin ameliorates dexamethasone-induced osteoporosis by regulation of the RANK/RANKL/OPG signaling pathway," Drug Design, Development Therapy, vol. 14, pp. 195-206, 2020.

[7] S. K. Wong, N. V. Mohamad, T. R. Giaze, K. Y. Chin, N. Mohamed, and S. Ima-Nirwana, "Prostate cancer and bone metastases: the underlying mechanisms," International Journal of Molecular Sciences, vol. 20, no. 10, p. 2587, 2019.

[8] P. A. V. Dam, Y. Verhoeven, J. Jacobs et al., "RANK-RANKL signaling in cancer of the uterine cervix: a review," International Journal of Molecular Sciences, vol. 20, no. 9, p. 2183, 2019.

[9] X. Wan, Y. Song, H. Fang et al., "RANKL/RANK promotes the migration of gastric cancer cells by interacting with EGFR," Clinical and Translational Medicine, vol. 9, no. 1, p. 3, 2020.

[10] M. Sisay, G. Mengistu, and D. Edessa, "The RANK/RANKL/ OPG system in tumorigenesis and metastasis of cancer stem cell: potential targets for anticancer therapy," Onco Targets and Therapy, vol. 10, pp. 3801-3810, 2017.

[11] B. Navet, K. Ando, J. W. Vargas-Franco et al., "The intrinsic and extrinsic implications of RANKL/RANK signaling in osteosarcoma: from tumor initiation to lung metastases," Cancers (Basel), vol. 10, no. 11, p. 398, 2018.

[12] N. E. Kushlinskii, E. S. Gershtein, Y. N. Solov'ev et al., "Receptor activator of nuclear transcription factor NF- $\kappa \mathrm{B}$ (RANK), its ligand RANKL, and natural inhibitor of RANKL osteoprotegerin (OPG) in the blood serum of patients with primary bone tumors," Bulletin of Experimental Biology and Medicine, vol. 163, pp. 478-481, 2017.

[13] X. Wu, F. Li, L. Dang, C. Liang, A. Lu, and G. Zhang, "RANKL/RANK system-based mechanism for breast cancer bone metastasis and related therapeutic strategies," Frontiers in Cell and Developmental Biology, vol. 8, p. 76, 2020.

[14] F. Christoph, F. König, S. Lebentrau et al., "RANKL/RANK/ OPG cytokine receptor system: mRNA expression pattern in $\mathrm{BPH}$, primary and metastatic prostate cancer disease," World Journal of Urology, vol. 36, no. 2, pp. 187-192, 2018.

[15] K. Takayama, T. Inoue, S. Narita et al., "Inhibition of the RANK/RANKL signaling with osteoprotegerin prevents castration-induced acceleration of bone metastasis in castration-insensitive prostate cancer," Cancer Letters, vol. 397, pp. 103-110, 2017.

[16] S. Bernardi, R. Voltan, E. Rimondi et al., "TRAIL, OPG, and TWEAK in kidney disease: biomarkers or therapeutic targets?" Clinical Science, vol. 133, no. 10, pp. 1145-1166, 2019.

[17] Y. Sambandam, P. Ethiraj, J. D. Hathaway-Schrader et al., "Autoregulation of RANK ligand in oral squamous cell carcinoma tumor cells," Journal of Cellular Physiology, vol. 233, no. 8, pp. 6125-6134, 2018.

[18] E. Ahern, A. Cubitt, E. Ballard et al., "Pharmacodynamics of pre-operative PD1 checkpoint blockade and receptor activator of NFkB ligand (RANKL) inhibition in non-small cell lung cancer (NSCLC): study protocol for a multicentre, open- label, phase $1 \mathrm{~B} / 2$, translational trial (POPCORN)," Trials, vol. 20, no. 1, p. 753, 2019.

[19] M. V. Deligiorgi, H. Mahaira, C. Eftychiadis et al., "RANKL, OPG, TRAIL, KRas, and c-Fos expression in rela-tion to central lymph node metastases in papillary thyroid carcinoma," Official Journal of the Balkan Union of Oncology, vol. 23, no. 4, pp. 1029-1040, 2018.

[20] J. Ferguson, D. J. Wilcock, S. McEntegart et al., "Osteoblasts contribute to a protective niche that supports melanoma cell proliferation and survival," Pigment Cell \& Melanoma Research, vol. 33, no. 1, pp. 74-85, 2020.

[21] G. Ding, X. Gu, Z. Dai et al., "Association of genetic polymorphisms in FOXA1 with the progression of genetic susceptibility to gastric cancer," Gastroenterology Research and Practice, vol. 2020, pp. 1-8, 2020.

[22] B. B. de Castilhos, C. M. de Souza, M. L. S. S. N. Fontana et al., "Association of clinical variables and polymorphisms in RANKL, RANK, and OPG genes with external apical root resorption," American Journal of Orthodontics and Dentofacial Orthopedics, vol. 155, no. 4, pp. 529-542, 2019.

[23] B. Mrozikiewicz-Rakowska, P. Nehring, K. Szymański et al., "Selected RANKL/RANK/OPG system genetic variants in diabetic foot patients," Journal of Diabetes \& Metabolic Disorders, vol. 17, no. 2, pp. 287-296, 2018.

[24] L. Casas-Avila, V. Ponce de León-Suárez, R. I. PeñalozaEspinosa et al., "The RANKL rs12585014 polymorphism is associated with age at menarche in postmenopausal women with hip fracture," Gynecological Endocrinology, vol. 34, no. 12, pp. 1031-1034, 2018.

[25] R. Sassi, H. Sahli, E. Cheour, S. Sellami, and A. B. A. E. Gaaied, “-643C> T RANKL gene polymorphism is associated with osteoporosis in tunisian postmenopausal women," Climacteric, vol. 20, no. 4, pp. 374-378, 2017.

[26] O. G. Shaker and M. A. Senousy, "Association of SNP-SNP interactions between RANKL, OPG, CHI3L1, and VDR genes with breast cancer risk in Egyptian women," Clinical Breast Cancer, vol. 19, no. 1, pp. e220-e238, 2019.

[27] P. F. C. D. Lucas Corso, M. N. Meger, I. B. F. Petean et al., "Examination of OPG, RANK, RANKL and HIF1A polymorphisms in temporomandibular joint ankylosis patients," Journal of Cranio-Maxillofacial Surgery, vol. 47, no. 5, pp. 766-770, 2019.

[28] J. Yin, L. Wang, W. Tang et al., "Rank rs1805034 t>c polymorphism is associated with susceptibility of esophageal cancer in a Chinese population," PLoS One, vol. 9, no. 7, Article ID e101705, 2014.

[29] M. Abudawood, "Diabetes and cancer: a comprehensive review," Journal of Research in Medical Science, vol. 24, no. 1, p. 94, 2019.

[30] Z. F. Miao, H. Xu, Y. Y. Xu et al., "Diabetes mellitus and the risk of gastric cancer: a meta-analysis of cohort studies," Oncotarget, vol. 8, no. 27, pp. 44881-44892, 2017.

[31] M. Inoue, M. Iwasaki, T. Otani et al., "Diabetes mellitus and the risk of cancer: results from a large-scale population-based cohort study in Japan," Archives of Internal Medicine, vol. 166, no. 17, pp. 1871-1877, 2006.

[32] X. Jiang, L. Bernstein, C. C. Tseng, and A. H. Wu, "Diabetes and risk of esophageal and gastric adenocarcinomas," International Journal of Cancer, vol. 131, no. 6, pp. 1417-1422, 2012.

[33] B. Carstensen, D. R. Witte, and S. Friis, "Cancer occurrence in danish diabetic patients: duration and insulin effects," Diabetologia, vol. 55, no. 4, pp. 948-958, 2012.

[34] M. Khan, M. Mori, Y. Fujino et al., "Sitespecific cancer risk due to diabetes mellitus history: evidence from the Japan 
collaborative cohort (JACC) study," Asian Pacific Journal of Cancer Prevention, vol. 7, pp. 253-259, 2006.

[35] H. L. Xu, Y. T. Tan, M. Epplein et al., "Population-based cohort studies of type 2 diabetes and stomach cancer risk in Chinese men and women," Cancer Science, vol. 106, pp. 294-298, 2015.

[36] M. Pollak, "The insulin and insulin-like growth factor receptor family in neoplasia: an update," Nature Reviews Cancer, vol. 12, no. 3, pp. 159-169, 2012.

[37] N. Siddavaram, "Carcinoma of the stomach: a review of epidemiology, pathogenesis, molecular genetics and chemoprevention," World Journal of Gastrointestinal Oncology, vol. 4, no. 7, pp. 156-169, 2012. 